\title{
Perilaku Menonton dan Kepuasan Petani terhadap Program Merajut Asa di Televisi TV Trans7
}

\section{Viewing Behavior and Farmer's Satisfaction of "Merajut Asa" in TV Trans7}

\author{
Nurlaila Kusuma $^{1}$, Hadiyanto ${ }^{1}$ \\ ${ }^{1}$ Departemen Sains Komunikasi dan Pengembangan Masyarakat, \\ Fakultas Ekologi Manusia, Institut Pertanian Bogor, Bogor
}

\begin{abstract}
This study aims to identify the behavior of the audience watching television, as well as analyzed the relationship between viewing behavior with the level of audiences satisfaction the programs Merajut Asa TV Trans7. The method was used in this study is a survey method with the quantitative approaches supported by qualitative data. The results of this study explain the choice of the most popular by farmers is the program information and entertainment. Farmers have a low duration of watching television, i.e. during 7,50-45,75 minutes/day, as well as the duration of watching programs Merajut Asa TV Trans7 also low, i.e. during 1-15 minutes. Farmers have a low frequency of watching television, the only watch 1-4 times a week. Frequency of watching programs Merajut Asa TV Trans 7 also low, i.e. 1-2 times a month. Duration of watching is not associated with the level of audiences satisfaction. Frequency of watching associated with the level of audiences satisfaction, i.e. satisfaction information.
\end{abstract}

Keywords: viewing behavior, viewing satisfaction, merajut asa program, TV

\begin{abstract}
Abstrak
Penelitian ini bertujuan mengidentifikasi perilaku khalayak dalam menonton program acara televisi, serta menganalisis hubungan perilaku menonton dengan tingkat kepuasan khalayak terhadap program Merajut Asa TV Trans7. Metode yang digunakan dalam penelitian ini adalah metode survei dengan pendekatan kuantitatif yang didukung data kualitatif. Hasil penelitian ini menjelaskan pilihan acara yang paling digemari oleh petani adalah program informasi dan hiburan. Petani memiliki durasi menonton televisi yang tergolong rendah, yaitu selama 7,50-45,75 menit/hari, begitu pula dengan durasi menonton program Merajut Asa TV Trans7 juga tergolong rendah, yaitu selama 1-15 menit. Petani memiliki frekuensi menonton televisi yang rendah, yaitu hanya menonton 1-4 kali dalam seminggu. Frekuensi menonton program Merajut Asa di TV Trans7 juga rendah, yaitu 1-2 kali dalam sebulan. Durasi menonton tidak berhubungan dengan tingkat kepuasan khalayak. Frekuensi menonton berhubungan dengan tingkat kepuasan khalayak, yaitu kepuasan informasi.
\end{abstract}

Kata kunci: perilaku menonton, kepuasan menonton, program merajut asa, televisi

\section{Pendahuluan}

Televisi memegang peran penting dalam menyediakan informasi yang cepat sehingga televisi banyak diminati. Proses atau cara pengendalian dapat dilihat melalui berbagai kebijakan (Wahyuni, 2000). Menurut UU No.32 Tahun 2002 tentang Penyiaran, lembaga penyiaran adalah penyelenggara penyiaran, baik lembaga penyiaran publik, lembaga penyiaran swasta, serta lembaga penyiaran komunitas maupun lembaga penyiaran berlangganan yang dalam melaksanakan tugas, fungsi, dan tanggung jawabnya berpedoman pada peraturan perundang-undangan yang berlaku.

Jika dilihat dari fungsinya, media penyiaran adalah sebagai kontrol dan perekat sosial. Selain itu, media penyiaran berfungsi menjadi sarana bagi kebudayaan sekaligus ekonomi. Seperti yang dikatakan Mahfudz Siddiq bahwa isi siaran memiliki efek besar bagi kehidupan masyarakat. Beliau juga menyinggung mengenai terlalu banyaknya porsi tayangan hiburan yang disajikan ke masyarakat, padahal masyarakat juga membutuhkan tayangan yang edukatif dan informatif (KPI, 2013). Hal ini didukung oleh penelitian Hadiyanto (2004) yang menyatakan motif-motif menonton televisi yang utama adalah hiburan dan memperoleh informasi. Oleh karena itu, dibutuhkan program acara informasi yang berkualitas untuk memenuhi kebutuhan khalayak dalam mencari informasi.

Salah satu program acara informasi yang ada sekarang ini adalah Merajut Asa milik TV 
Trans7. Menurut website TV Trans7, Merajut Asa TV Trans7 mengangkat tentang permasalahan yang terjadi di masyarakat kecil dan memberikan solusi sehingga permasalahan tadi menjadi teratasi. Program acara ini terbagi menjadi tiga segmen yang masing-masing terdiri dari pengenalan masalah, upaya tokoh utama yang tergerak untuk melakukan suatu usaha memecahkan masalah yang terjadi, dan kisah keberhasilan dari tokoh tersebut dalam mencari solusi dari masalah. Lokasi liputan program acara ini di pelosok-pelosok desa seluruh Indonesia

Program Merajut Asa TV Trans7 sudah sesuai dengan yang telah ditetapkan dalam UU No 32 Tahun 2002 pasal 5 huruf f dan Peraturan KPI tentang Pedoman Perilaku Penyiaran Tahun 2012 pasal 22. Dengan demikian, program acara televisi yang dibutuhkan oleh khalayak adalah program acara yang mengandung unsur pemberdayaan masyarakat, terutama masyarakat desa yang masih bekerja dibidang pertanian. Serta program acara yang berisi cara melestarikan lingkungan sekitarnya, seperti program Merajut Asa TV Trans7.

Hadirnya program Merajut Asa TV Trans7 menambah pilihan acara bagi khalayak. Menurut West dan Turner (2008), teori kegunaan dan gratifikasi menyatakan bahwa orang secara aktif mencari media tertentu dan muatan (isi) tertentu untuk menghasilkan kepuasan atau hasil tertentu. Adanya kebutuhan yang berbeda dari setiap khalayak akan mempengaruhi perilaku mereka dalam memilih program acara televisi yang dianggap sesuai dengan minat dan kebutuhan. Menurut DeFleur dan Lowery (1994), perilaku menonton adalah kebiasaan dan tindakan dalam menonton siaran televisi karena dorongan dalam dirinya untuk menonton televisi. Perilaku menonton mencakup tiga aspek, yaitu pilihan acara, durasi menonton, dan frekuensi menonton. Perilaku menonton akan meningkat ketika semua kebutuhan terpenuhi. Hal ini didukung oleh penelitian Badriah (2003) yang menyatakan semakin tinggi durasi remaja menonton program acara hiburan maka akan semakin terpenuhi semua kebutuhan baik informasi, identitas pribadi, integrasi dan interaksi sosial, maupun hiburan.

Tujuan dari program Merajut Asa TV Trans 7 adalah untuk memberikan motivasi kepada penonton, khususnya masyarakat kecil yang berada di pedesaan terutama yang bekerja di bidang pertanian agar tidak menyerah pada keadaan dan ikut melestarikan lingkungan. Petani merupakan khalayak yang membutuhkan tokoh inspiratif yang dapat memberikan solusi dalam mengatasi beragam masalah pertanian serta dapat melestarikan lingkungan sekitarnya. Oleh karena itu, penelitian ini dilakukan di Desa Citapen, Kecamatan Ciawi, Kabupaten Bogor karena berdasarkan hasil penjajagan, daerah tersebut masih terdapat lahan pertanian dan warga yang tergolong sebagai petani. Melalui pemilihan program Merajut Asa TV Trans7 yang ditonton oleh petani dapat dilihat kepuasan khalayak dalam menonton yang didasari oleh perilaku khalayak dalam memilih program yang sesuai dengan kebutuhannya.

Berbagai program acara yang ditayangkan oleh stasiun televisi menambah pilihan khalayak dalam menonton. Seperti program Merajut Asa TV Trans7 yang merupakan salah satu program acara informasi dan menjadi pilihan khalayak. Banyaknya permasalahan sosial yang ada di lingkungan sekitar membuat khalayak khususnya masyarakat kecil yang berada di desa agar tidak menyerah pada keadaan dan tetap melestarikan lingkungan. Khalayak membutuhkan sebuah tayangan yang dapat memberikan informasi dan motivasi mengenai lingkungan sekitarnya. Pemilihan program acara di televisi tergantung dengan kebutuhan khalayak terhadap suatu tayangan, begitupun dalam memilih program Merajut Asa TV Trans7. Penelitian ini bertujuan untuk (1) mengidentifikasi perilaku petani dalam menonton program acara televisi, (2) Menganalisis hubungan perilaku menonton dengan tingkat kepuasan petani dalam menonton program Merajut Asa TV Trans7.

\section{Metode Penelitian}

Penelitian ini dilakukan di RW 05 Desa Citapen, Kecamatan Ciawi, Kabupaten Bogor, Provinsi Jawa Barat. Lokasi penelitian tersebut dipilih secara sengaja (purposive) dengan pertimbangan sebagai berikut: (1) Menurut keterangan penduduk pada observasi awal, di RW 05 program yang ditayangkan oleh TV Trans7 dapat dilihat dengan jernih dan jelas tanpa ada gangguan sinyal, banyak penduduk yang memiliki televisi diban-dingkan dengan RW lainnya di Desa Citapen. (2) Mayoritas penduduk RW 05 bermata pen-caharian sebagai petani, yang sesuai dengan sasaran program Merajut 


\section{Asa TV Trans7.}

Lokasi ini diharapkan dapat menjelaskan perilaku menonton dan kepuasan petani terhadap program Merajut Asa TV Trans7 di Desa Citapen. Penelitian ini dilaksanakan pada bulan April 2013. Penelitian survei adalah penelitian yang mengambil sampel dari populasi dan menggunakan kuesioner sebagai alat pengumpul data primer (Singarimbun dan Effendi, 1989). Populasi dalam penelitian ini adalah seluruh penduduk RW 05 Desa Citapen, Kecamatan Ciawi, Kabupaten Bogor. Unit analisa dalam penelitian ini adalah individu. Pengambilan sampel dilakukan dengan menggunakan teknik purposive sampling. Menurut Riduwan (2009), teknik purposive sampling adalah teknik sampling yang digunakan peneliti jika peneliti mempunyai pertimbangan tertentu di dalam pengambilan sampelnya atau penentuan sampel untuk tujuan tertentu.

Pengambilan sampel dilakukan melalui tahapan sebagai berikut: (1) Seluruh penduduk RW 05 Desa Citapen, Kecamatan Ciawi, Kabupaten Bogor diberikan angket sederhana berisi kebiasaan menonton, khususnya terhadap program Merajut Asa TV Trans7, dan kesediaan untuk menjadi responden. Hal ini dilakukan karena peneliti belum mengetahui profil populasi. (2) Setelah mengetahui responden yang memenuhi kedua indikator yang telah ditentukan yaitu menonton prog-ram Merajut Asa TV Trans7 dan bersedia menjadi responden. Dipilih penduduk yang bermata pencaharian di bidang pertanian untuk dijadikan sampel penelitian, karena sesuai dengan isi acara program Merajut Asa TV Trans7. Kemudian didapatkan sebanyak 46 orang buruh tani yang bersedia menjadi responden penelitian.

Jenis data yang dikumpulkan adalah data primer dan data sekunder. Data primer yang dikumpulkan meliputi data kuantitatif dan kualitatif. Data primer kuantitatif diperoleh dari wawancara terstruktur kepada responden dengan menggunakan instrumen berupa kuesioner yang terdiri dari pertanyaan tertutup, yaitu pertanyaan yang sudah disertai alternatifjawabannya. Selain data kuantitatif, kuesioner juga dilengkapi pertanyaan terbuka untuk menggali data kualitatif, yaitu pertanyaan berupa isian yang tidak disertai pilihan jawaban. Data sekunder dikumpulkan melalui Studi Pustaka dan data didapatkan dari Kantor Desa Citapen mengenai gambaran umum desa dan sumber-sumber sekunder mengenai TV Trans7, baik melalui website resmi TV Trans7 maupun Kantor Pusat TV Trans7 untuk mengetahui profil TV Trans7 dan profil program Merajut Asa TV Trans7.

Data yang diperoleh dianalisis dengan pendekatan kuantitatif. Data hasil kuesioner terhadap responden kemudian diolah secara statistik deskriptif dengan menggunakan software Statistic Program for Social Sciences (SPSS) for Windows versi 17.0 dan Microsoft Excel 2007. Data yang diperoleh akan dianalisis dengan beberapa teknik, antara lain: (1) Tabel frekuensi digunakan untuk menganalisis data primer, yaitu perilaku menonton dan tingkat kepuasan menonton. (2) Tabulasi silang, untuk dapat menerangkan hubungan antarvariabel dengan metode analisa sederhana, yaitu hubungan antara perilaku menonton dengan kepuasan menonton. (3) Uji korelasi rank Spearman untuk melihat hubungan nyata antarvariabel dengan data berbentuk ordinal dan data interval yang diubah menjadi data ordinal. Uji ini digunakan untuk menentukan hubungan antara kedua variabel (variabel independen dan variabel dependen) yang ada dalam penelitian ini, yaitu menguji hubungan antara perilaku menonton program Merajut Asa TV Trans7 (skala ordinal), seperti durasi menonton dan frekuensi menonton dengan tingkat kepuasan petani terhadap program Merajut Asa TV Trans7 (skala interval), seperti kepuasan informasi, kepuasan identitas pribadi, kepuasan integrasi dan identitas pribadi, dan kepuasan hiburan.

\section{Hasil dan Pembahasan}

\section{Program Acara TV Trans7}

Jenis program acara TV Trans7 dapat dikelompokkan menjadi dua bagian, yaitu program informasi dan program hiburan. Data selengkapnya mengenai jenis program acara TV Trans7 dapat dilihat pada Tabel 1.

\section{Program Merajut Asa TV Trans7}

Merajut Asa TV Trans7 tayang setiap hari Jumat pukul 17.00 WIB dengan durasi tayang 30 menit termasuk iklan. Program acara ini termasuk ke dalam program infor-masi, terdiri dari tiga segmen. 
Tabel 1 Jenis Program, Kategori Program, dan Nama Program Acara TV Trans7 Tahun 2013

\begin{tabular}{cll}
\hline $\begin{array}{c}\text { Jenis } \\
\text { program }\end{array}$ & \multicolumn{1}{c}{$\begin{array}{c}\text { Kategori } \\
\text { Program }\end{array}$} & Contoh program \\
\hline Informasi & Berita & Redaksi Pagi \\
& Infotainment & Selebrita Pagi \\
& Current affair & Selamat Pagi \\
& Magazines dan & Orang Pinggiran, \\
& documentary & Merajut Asa \\
& Talk show & Bukan Empat Mata \\
Hiburan & Musik & Kuku Bima Ener-G! \\
& & Konser7 \\
& Drama & Carrossel \\
& Permainan & Ga Nyangka \\
& Reality show & Ups Salah, Makan \\
& & Besar \\
& Sport & MotoGP \\
& Pertunjukan & Opera Van Java \\
\hline
\end{tabular}

Jumlah episode Merajut Asa TV Trans7 yang sudah ditayangkan sebanyak kurang lebih 32 episode. Salah satu tayangan Merajut Asa TV Trans7 adalah kisah pria bernama Saekan yang tergerak untuk melakukan gerakan penghijauan sejak tahun 1980-an di Desa Padas. Alasannya melakukan penghijauan karena di daerah perbukitan itu sulit sekali mendapatkan air bersih.

Saekan mulai menanam jenis tanaman "Kluwek" di daerah perbukitan tersebut. Beliau menemukan aliran air bersih di sekitar areal penghijauannya. Selain itu, wilayah tersebut sudah tampak berbeda dengan wilayah di sekitarnya, sehingga tampak paling hijau dan rimbun.

\section{Gambaran Umum Lokasi Penelitian}

Desa Citapen termasuk dalam wilayah Kecamatan Ciawi, Kabupaten Bogor, Provinsi Jawa Barat. Desa ini memiliki luas wilayah sebesar 268,66 ha dengan jumlah penduduk sebanyak 8.431 jiwa. Secara administratif, Desa Citapen terbagi atas dua dusun, tujuh Rukun Warga (RW), dan 26 Rukun Tetangga (RT). Desa Citapen berbatasan dengan Desa Banjarsari di sebelah Utara, dengan Desa Bojongjengkol dan Desa Tegalwaru di sebelah Timur, Desa Cicadas di sebelah Selatan, dan Desa Cibadak di sebelah Barat.
Tabel 2 Jumlah dan Persentase Responden berdasarkan Pilihan Acara di Desa Citapen tahun 2013

\begin{tabular}{lcc}
\hline \multicolumn{1}{c}{ Pilihan acara } & Jml. & (\%) Persen \\
& (orang) & \\
\hline Informasi & 12 & 26,09 \\
Hiburan & 4 & 8,70 \\
Informasi dan hiburan & 30 & 65,21 \\
\hline Total & 46 & 100,00 \\
\hline
\end{tabular}

Wilayah di Desa Citapen digunakan untuk pemukiman dan pekarangan seluas 110,37 ha dan sawah seluas 140 ha. Melihat kondisi tersebut, menyebabkan sebagian penduduk di Desa Citapen bermata pencaharian di bidang pertanian, yaitu sebanyak 589 jiwa. Pekerjaan ini dilakukan setiap hari, kecuali hari Jumat karena pada hari itu banyak petani yang mengikuti pengajian pada pagi hari dan setelah itu sebagian petani laki-laki melaksanakan ibadah shalat Jumat. Lahan pertanian yang mereka kerjakan sebagian besar bukan milik mereka, tetapi milik orang Jakarta.

\section{Perilaku Menonton Program Merajut Asa TV Trans7}

Pilihan Acara. Pilihan acara dalam penelitian ini merupakan program acara televisi yang ditonton oleh responden. Pilihan acara dibagi menjadi dua kategori siaran, yaitu program acara informasi dan program acara hiburan. Data selengkapnya mengenai pilihan acara responden penelitian (Tabel 2). Tabel 2 menunjukkan bahwa persen-tase responden yang menonton program acara informasi dan hiburan lebih besar, yaitu sebesar 65,21\% atau 30 orang. Hal ini menunjukkan mayoritas responden yang dilibatkan dalam penelitian ini menonton program acara informasi dan hiburan. Jenis program acara informasi yang paling sering disaksikan adalah berita, seperti Liputan 6, Seputar Indonesia, Reportase, dan Apa Kabar Indonesia. Hal ini karena para responden membutuhkan informasi terbaru yang terjadi di daerah lain, terutama tentang peristiwa penting dan bencana alam.

Program acara yang paling digemari responden adalah program acara hiburan, yaitu program acara permainan dan sinetron. Mayoritas responden menyukai pertandingan sepak bola dan 
Tabel 3 Jumlah dan Persentase Responden berdasarkan Durasi Menonton Televisi di Desa Citape Tahun 2013

\begin{tabular}{lccc}
\hline \multicolumn{1}{c}{$\begin{array}{c}\text { Durasi } \\
\text { menonton }\end{array}$} & Kategori & $\begin{array}{c}\text { Jml. } \\
\text { (orang) }\end{array}$ & $\begin{array}{c}\text { Persen } \\
\text { (\%) }\end{array}$ \\
\hline $\begin{array}{l}7,50-45,75 \\
\text { menit/hari }\end{array}$ & Rendah & 24 & 52,17 \\
$\begin{array}{l}45,76-95,00 \\
\text { menit/hari }\end{array}$ & Tinggi & 22 & 47,83 \\
\hline Total & & 46 & 100,00 \\
\hline
\end{tabular}

acara permainan yang membutuhkan ketangkasan. Pada malam hari, responden khususnya ibu-ibu lebih sering menyaksikan sinetron karena menghibur dan alur cerita yang mempunyai kelanjutan menyebabkan ibu-ibu selalu menonton tayangan ini.

Durasi Menonton. Durasi menonton televisi adalah lamanya waktu yang digunakan oleh responden dalam menyaksikan acara televisi perhari disajikan pada Tabel 3. Tabel 3 menunjukkan mayoritas responden memiliki durasi menonton rendah lebih besar, yaitu sebesar 52,17\% atau 24 orang. Hal ini menunjukkan bahwa mayoritas responden yang dilibatkan dalam penelitian ini memiliki durasi menonton televisi yang rendah. Sementara, proporsi persentase responden yang memiliki durasi menonton tinggi, yaitu hanya sebesar $47,83 \%$ atau 22 orang. Durasi menonton televisi yang rendah disebabkan karena responden tidak fokus menonton televisi, ada kegiatan lain yang dilakukan responden ketika sedang menonton televisi.

Durasi Menonton Program Merajut Asa TV Trans7. Durasi menonton program Merajut Asa TV Trans 7 adalah lamanya waktu yang digunakan oleh responden dalam menyaksikan program Merajut Asa TV Trans7 dalam sekali tayang pada episode terakhir yang disaksikan oleh responden. Program ini berdurasi 30 menit dengan jam tayang dari pukul 17.00 sampai 17.30 WIB. Sebanyak $86,96 \%$ responden memiliki durasi menonton rendah terhadap program Merajut Asa TV Trans7, yaitu hanya sekitar kurang dari 15 menit. Sementara, sisanya sebanyak $13,04 \%$ responden memiliki durasi menonton yang lebih 15 menit. Mayoritas responden yang menonton program Merajut Asa TV Trans7 hanya sekilas dan berganti ke program
Tabel 4 Jumlah dan Persentase Responden berdasarkan Durasi Menonton Program Merajut Asa TV Trans7di Desa Citapen tahun 2013

\begin{tabular}{|c|c|c|c|}
\hline $\begin{array}{c}\text { Durasi } \\
\text { menonton }\end{array}$ & Kategori & $\begin{array}{c}\text { Jml. } \\
\text { (orang) }\end{array}$ & $\begin{array}{c}\text { Persen } \\
(\%)\end{array}$ \\
\hline $1-15$ menit & Rendah & 40 & 86,96 \\
\hline $16-30$ menit & Tinggi & 6 & 13,04 \\
\hline Total & & 46 & 100,00 \\
\hline
\end{tabular}

acara lain. Responden menonton program acara ini hanya untuk mengisi waktu luang pada saat tidak ada aktivitas apapun.

\section{Frekuensi Menonton Program Merajut Asa TV Trans7}

Frekuensi menonton program Merajut Asa TV Trans7 adalah tingkat keseringan responden dalam menyaksikan program Merajut Asa Trans7 se lama satu bulan terakhir. Program Merajut Asa TV Trans7 ditayangkan setiap hari Jumat pada pukul 17.00 sampai 17.30 WIB. Program acara ini tayang sekali dalam seminggu, sehingga dalam sebulan hanya ada 4 kali.

Responden memiliki tingkat frekuensi menonton rendah terhadap program Merajut Asa TV Trans7, yaitu sebesar 67,39\% responden. Sebanyak $32,61 \%$ responden memiliki frekuensi menonton yang tinggi. Frekuensi tayang yang hanya seminggu sekali membuat responden jarang menonton program Merajut Asa TV Trans7. Selain itu, setiap hari Jumat responden yang bekerja sebagai petani tidak pergi bekerja dan memilih mengisi waktu luang dengan menambah pengetahuan tentang informasi dari berbagai tayangan televisi.

\section{Hubungan Perilaku Menonton Dan Tingkat Kepuasan Menonton Terhadap Program Merajut Asa TV Trans7}

Indikator kepuasan merupakan terpenuhinya kebutuhan dari setiap individu. Setiap individu akan menggunakan media yang sesuai dengan apa yang diharapkan dan dibutuhkannya. Tingkat kepuasan khalayak tersebut terbagi menjadi empat bagian, antara lain: kepuasan informasi, kepuasan identitas pribadi, kepuasan integrasi dan interaksi sosial, serta 
Tabel 5 Jumlah dan Persentase Responden berdasarkan Frekuensi Menonton Program Merajut Asa TV Trans7 di Desa Citapen tahun 2013

\begin{tabular}{lccc}
\hline $\begin{array}{l}\text { Frekuensi } \\
\text { menonton }\end{array}$ & Kategori & $\begin{array}{c}\text { Jml. } \\
\text { (orang) }\end{array}$ & $\begin{array}{c}\text { Persen } \\
\text { (\%) }\end{array}$ \\
\hline 1-2 kali & Rendah & 31 & 67,39 \\
3-4 kali & Tinggi & 15 & 32,61 \\
\hline Total & & 46 & 100,00 \\
\hline
\end{tabular}

kepuasan hiburan (Tabel 6). Kepuasan informasi, kepuasan bagi identitas pribadi, kepuasan integrasi dan interaksi sosial, dan kepuasan hiburan termasuk dalam kategori tinggi. Hal ini menjelaskan bahwa responden yang menonton program Merajut Asa TV Trans 7 merasa kebutuhan akan informasi, identitas pribadi, integrasi dan interaksi sosial, serta hiburan. Kebutuhan yang dimiliki oleh responden yang bekerja sebagai buruh tani mendorongnya untuk menonton program Merajut Asa TV Trans7 sehingga menghasilkan tingkat kepuasan yang tinggi dalam menonton.

Rataan skor paling tinggi dimiliki oleh kepuasan identitas pribadi, didukung oleh item yang berisi pernyataan tentang "Membuat saya lebih percaya diri bahwa keluarga tani juga dapat sukses". Responden merasa puas bahwa setelah menonton program Merajut Asa TV Trans7 hanya dengan bertani mereka dapat sukses. Sementara itu, rataan skor terendah adalah kepuasan integrasi dan interaksi sosial. Hal ini disebabkan program Merajut Asa TV Trans7 hanya menjadi bahan obrolan dengan keluarga, tetangga, maupun petani mengenai kondisi petani di daerah lain.

Tingkat kepuasan menonton responden berada dalam kategori tinggi, hal ini juga terjadi pada masing-masing kepuasan, yang meliputi kepuasan informasi, kepuasan identitas pribadi, kepuasan integrasi dan interaksi sosial, maupun kepuasan hiburan. Hal ini disebabkan responden merasa terpenuhi kebutuhannya setelah menonton program Merajut Asa TV Trans7, seperti mendapatkan pengetahuan dalam bidang pertanian, dapat dijadikan bahan obrolan, baik dengan keluarga, tetangga, maupun petani lainnya. Jika tidak ada aktivitas mereka juga mempunyai kebiasaan mengisi waktu luang dengan menonton televisi.

Nilai koefisien korelasi antara durasi
Tabel 6 Rataan skor tingkat kepuasan menonton di Desa Citapen tahun 2013

\begin{tabular}{lr}
\hline Tingkat kepuasan menonton & $\begin{array}{c}\text { Rataan } \\
\text { Skor* }\end{array}$ \\
\hline Kepuasan informasi & 3,96 \\
Kepuasan identitas pribadi & 4,08 \\
Kepuasan integrasi dan interaksi sosial & 3,61 \\
Kepuasan hiburan & 4,05 \\
\hline Keterangan: *Interval skor: & $2,00-3,50=$ rendah; \\
& $3,51-5,00=$ tinggi
\end{tabular}

menonton dengan tingkat kepuasan menonton diperoleh dari hasil uji statistik korelasi rank Spearman. Data selengkapnya mengenai nilai koefisien korelasi durasi menonton dengan tingkat kepuasan menonton program Merajut Asa TV Trans 7 dapat dilihat pada Tabel 7. Tabel 7 menunjukkan hasil uji hubungan antara durasi menonton dengan tingkat kepuasan menonton program Merajut Asa TV Trans7. Dapat dilihat dari hasil uji tersebut durasi menonton tidak berhubungan dengan tingkat kepuasan menonton program MerajutAsa TV Trans7. Terbukti dari hasil uji statistik bahwa tidak terdapat hubungan nyata antara durasi menonton dengan tingkat kepuasan menonton baik kepuasan informasi, kepuasan identitas pribadi, kepuasan integrasi dan interaksi sosial, maupun kepuasan hiburan. Hal ini tidak sejalan dengan penelitian Badriah (2003) yang menyatakan bahwa semakin tinggi durasi menonton maka semakin terpenuhi kebutuhan remaja akan acara hiburan. Responden menonton program acara Merajut Asa diselingi dengan menonton program acara dari stasiun televisi lain sehingga durasi menonton program acara tersebut rendah. Karena pada sore hari mereka menonton televisi hanya untuk mengisi waktu luang dan bersantai bersama keluarga. Kebiasaan ini menyebabkan durasi menonton program Merajut Asa TV Trans7 rendah. Sementara itu, untuk memenuhi kebutuhan informasi, responden lebih sering menonton program informasi lain, yaitu berita. Berita yang disaksikan antara lain Liputan 6, Seputar Indonesia, Reportase, dan Apa Kabar Indonesia. Program acara berita juga ditayangkan pada sore hari sehingga menyebabkan durasi menonton responden semakin rendah untuk menonton program Merajut Asa TV Trans7.

Berdasarkan uji korelasi rank Spearman diperoleh nilai signifikansi $0,037<0,05$ (taraf nyata) 
Tabel 7 Nilai Koefisien Korelasi dan Signifikansi Durasi Menonton dengan Tingkat Kepuasan Menonton Program Merajut Acara TV Trans7 di Desa Citapen Tahun 2013

\begin{tabular}{|c|c|c|}
\hline \multirow{2}{*}{$\begin{array}{l}\text { Tingkat kepuasan } \\
\text { menonton }\end{array}$} & \multicolumn{2}{|c|}{ Durasi menonton } \\
\hline & $\begin{array}{c}\text { Koefisien } \\
\text { korelasi }\end{array}$ & $\begin{array}{l}\text { Sig. (2- } \\
\text { tailed) }\end{array}$ \\
\hline Kepuasan informasi & $-0,265$ & 0,750 \\
\hline Kepuasan identitas pribadi & 0,083 & 0,585 \\
\hline $\begin{array}{l}\text { Kepuasan integrasi dan } \\
\text { interaksi sosial }\end{array}$ & $-0,144$ & 0,341 \\
\hline Kepuasan hiburan & 0,120 & 0,429 \\
\hline
\end{tabular}

artinya terdapat hubungan nyata antara frekuensi menonton dengan kepuasan informasi. Semakin tinggi tingkat frekuensi menonton maka semakin tinggi kepuasan informasi responden terhadap program Merajut Asa TV Trans7. Responden menonton program Merajut Asa TV Trans7 karena merasa terpenuhi kebutuhan akan informasi terutama informasi di bidang pertanian. Ada juga beberapa responden yang menonton program ini untuk menambah pengetahuan. Hal ini didukung oleh pernyataan salah satu responden sebagai berikut.

\section{"Saya sering menonton acara Merajut Asa karena abis nonton jadi tahu cara ilangin hama, jaga kesuburan tanah, dan banyak informasi pertanian yang saya dapatkan."(Mp, 32 tahun)}

Sementara itu, variabel lainnya dalam tingkat kepuasan menonton program Merajut Asa TV Trans7, seperti kepuasan identitas pribadi, kepuasan integrasi dan interaksi sosial, dan kepuasan hiburan tidak terbukti memiliki hubungan nyata dengan frekuensi menonton. Hasil penelitian ini menunjukkan bahwa hipotesis penelitian yang menyatakan "terdapat hubungan antara perilaku menonton (durasi menonton, frekuensi menonton) dengan tingkat kepuasan petani terhadap program Merajut Asa TV Trans7" tidak sepenuhnya diterima. Hal ini dikarenakan tidak semua subvariabel perilaku menonton berhubungan dengan subvariabel tingkat kepuasan menonton. Rataan skor paling tinggi dimiliki oleh kepuasan identitas pribadi, didukung oleh item yang berisi pernyataan tentang "Membuat saya lebih percaya diri bahwa keluarga tani juga dapat sukses"

\section{Kesimpulan}

Petani di Desa Citapen memiliki kebiasaan menonton program acara informasi dan program acara hiburan. Namun, petani di Desa Citapen memiliki durasi rendah dalam menonton program acara televisi. Sama halnya dengan frekuensi menonton petani yang tergolong rendah dalam menonton program acara televisi. Sementara itu, untuk program Merajut Asa TV Trans7, petani di Desa Citapen juga memiliki durasi menonton dan frekuensi menonton yang rendah.

Tingkat kepuasan menonton program Merajut Asa TV Trans7 yang dimiliki oleh petani di Desa Citapen tergolong tinggi, baik untuk kepuasan informasi, kepuasan identitas pribadi, kepuasan integrasi dan interaksi sosial, serta kepuasan hiburan. Perilaku menonton program Merajut Asa TV Trans7, yaitu durasi menonton tidak memiliki hubungan nyata dengan tingkat kepuasan menonton, baik untuk kepuasan informasi, kepuasan identitas pribadi, kepuasan integrasi dan interaksi sosial, serta kepuasan hiburan. Sementara itu, frekuensi menonton Merajut Asa TV Trans7 memiliki hubungan dengan tingkat kepuasan menonton, yaitu kepuasan informasi. Frekuensi menonton berhubungan nyata (negatif) dengan kepuasan informasi. Namun, untuk kepuasan identitas pribadi, kepuasan integrasi dan interaksi sosial, serta kepuasan hiburan tidak memiliki hubungan nyata dengan frekuensi menonton.

\section{Daftar Pustaka}

Andremica A. 2010. Hubungan motivasi dan pola menonton dengan tingkat kepuasan mahasiswa terhadap program berita TV One (kasus mahasiswa Departemen Sains Komunikasi dan Pengembangan Masyarakat, FEMA, IPB) [skripsi]. Bogor (ID): Institut Pertanian Bogor.

Ardianto E, Karlinah S, Komala L. 2007. Komunikasi Massa: Suatu Pengantar. Ed Revisi. Bandung (ID): Simbiosa Rekatama Media.

Badriah. 2003. Motivasi, perilaku dan pemenuhan kebutuhan remaja dari acara hiburan televisi (perbandingan pada siswa SLTP Islam Teluk Jambe dan SLTP Negeri 6 Karawang, Kabupaten 
Karawang) [skripsi]. Bogor(ID): Institut Pertanian Bogor.

Daryanto. 2010. Ilmu Komunikasi. Bandung (ID): Sarana Tutorial Nurani Sejahtera.

DeFleur ML, SA Lowery. 1994. Milestones in Mass Communication Research: Media Effects. Ed ke-3. USA (US): Longman Publishers.

Desa Citapen. 2013. Data Monografi Desa Citapen. Bogor (ID): Kantor Desa Citapen.

Effendy OU. 1993. Ilmu, Teori, dan Filsafat Komunikasi. Bandung (ID): PT Citra Aditya Bakti.

Hadiyanto. 2004. Perilaku dan motif menonton televisi pada peternak di dua tipologi desa di Kabupaten Bogor. Jurnal Media Peternakan [Internet]. [dapat diunduh dari: http://journal. ipb.ac/index.php/mediapeternakan/article/ view/708/187.pdf].

Hofmann R. 1999. Dasar-dasar Apresiasi Program Televisi: Menjadikan Televisi Budaya Rakyat. Jakarta (ID): Grasindo.

[KPI] Komisi Penyiaran Indonesia. 2012. Peraturan Komisi Penyiaran Indonesia tentang Pedoman Perilaku Penyiaran (P3) dan Standar Program Siaran (SPS) Tahun 2012 [Internet]. [dapat diunduh dari: http://www.kpi. go.id].

[KPI] Komisi Penyiaran Indonesia. 2013. Literasi Media Membentuk Pemahaman dan Kepedulian Masyarakat terhadap Isi Siaran. [Internet]. [dapat diunduh dari: http://www.kpi.go.id/ index.php].

Kusumah FA. 2010. Motivasi dan perilaku menonton serta penilaian khalayak terhadap program acara televisi lokal (kasus pemirsa Megaswara TV di RW 01 Kelurahan Bojong Rangkas Kecamatan Ciampea, Kabupaten Bogor dan
RW 17 Kelurahan Tegal Gundil Kecamatan Bogor Utara, Kota Bogor). [skripsi]. Bogor (ID): Institut Pertanian Bogor.

McQuail D. 1991. Teori Komunikasi Massa: Suatu Pengantar. Ed ke-2. Jakarta (ID): Erlangga.

Morissan. 2005. Media Penyiaran: Strategi Mengelola Radio dan Televisi. Tanggerang (ID): Raminda Prakarsa.

Riduwan. 2009. Pengantar Statistika Sosial. Pristiwanto, editor. Bandung (ID): Penerbit Alfabeta.

Riswandi. 2009. Dasar-dasar Penyiaran. Ed Pertama. Yogyakarta (ID): Graha Ilmu.

Siegel S. 1985. Statistik Nonparametrik untuk IlmuIlmu Sosial. Hagul P, penerjemah. Terjemahan dari: Nonparametric Statistics for the Behavioral Sciences. Jakarta (ID): PT Gramedia.

Singarimbun M, Effendi S. 1989. Metode Penelitian Survai. Jakarta (ID): Lembaga Penelitian, Pendidikan, dan Penerangan Ekonomi dan Sosial (LP3ES).

TV Trans7. Profil Merajut Asa TV Trans7 [Internet]. [dapat diunduh dari: http://www.TV Trans7. co.id].

[UU] Undang-undang. 2002. Undang-Undang No. 32 Tahun 2002 tentang Penyiaran [Internet]. [dapat diunduh dari: http://www.kpi.go.id].

Wahyuni HI. 2000. Televisi dan Intervensi Negara: Konteks Politik Kebijakan Publik Industri Penyiaran Televisi pada Era Orde Baru.Yogyakarta (ID): Media Pressindo.

WestR, LHTurner. 2008. Pengantar Teori Komunikasi: Analisis dan Aplikasi. Ed ke-3. Maer MN, penerjemah. Jakarta (ID): Salemba Humanika. Terjemahan dari: Introducing Communication Theory: Analysis and Application. 